\title{
Рост упорядоченного массива вертикальных нанопроволок $\mathrm{VO}_{2}$
}

\author{
С.В. Мутилин ${ }^{1, *}$, В.Я. Принц ${ }^{1}$, В.А. Селезнев ${ }^{1}$, Л.В. Яковкина ${ }^{2}$ \\ ${ }^{1}$ Институт физики полупроводников им. А.В. Ржанова СО РАН \\ ${ }^{2}$ Институт неорганической химии им. А.В. Николаева СО РАН \\ *E-mail: mutilin@isp.nsc.ru
}

DOI:10.31868/RFL2018.23-24

Диоксид ванадия $\left(\mathrm{VO}_{2}\right)$ с сильно коррелированными электронами является интеллектуальным материалом, претерпевающим резкий, обратимый фазовый переход полупроводник-металл под действием температуры, электричества, излучения, механических напряжений [1]. Во время фазового перехода оптические, электрические и механические свойства $\mathrm{VO}_{2}$ испытывают значительные изменения. Такие уникальные свойства перехода могут быть использованы в микро/наноэлектронных устройствах и фотонных приложениях, таких как перестраиваемые метаматериаллы, оптические ограничители, ультрабыстрые оптические переключатели, фотонные кристаллы [2].

В последние годы наблюдается устойчивая тенденция исследования одиночных монокристаллов $\mathrm{VO}_{2}$. Проведенные исследования показывают, что монокристалл $\mathrm{VO}_{2}$ имеет более яркие свойства фазового перехода. Действительно, переход от поликристаллической структуры к монокристаллической за счет отсутствия межзеренных границ позволяет на несколько порядков увеличить число повторений, которое превосходит $10^{10}[3]$. Боле того, в отличие от поликристаллической пленки с шириной гистерезиса около 3-5 К, в монокристалле ширина гистерезиса сужается до 1-3K [4]. Такой резкий скачек достигается за счет того, что фазовый переход в монокристалле от фазы $\mathrm{M}$ в фазу $\mathrm{R}$ и обратно идет единым фронтом, в отличие от перехода в поликристаллической пленке, где переход идет перколяционно [5].

До сих пор исследовались единичные монокристаллы $\mathrm{VO}_{2}$ расположенные на подложках в случайном месте и имеющие случайные размеры в результате синтеза. Очевидно, что для практического применения нужны упорядоченные массивы одинаковых монокристаллов, расположенные в заданном месте и заданных размеров. Такие объекты являются метаповерхностями в ИК и ТГц областях, и могут быть использованы при создании умных метаматериалов, фотонных кристаллов и пр. В данной работе сообщается о формировании упорядоченного массива монокристаллических нанопроволок $\mathrm{VO}_{2}$ с помощью селективного роста на периодических 3D структурах кремния полученных с помощью наноимпринт-литографии.

Массивы нанопроволок $\mathrm{VO}_{2}$ были выращены с помощью газофазной эпитаксии с использованием прекурсора ванадил ацетилацетата на наноструктурированной подложке [6]. Наноструктурирование подложки было выполнено при помощи наноимпринт литографии на больших площадях (около $15 \mathrm{x} 15$ см) кремниевой пластины. Кристаллы $\mathrm{VO}_{2}$ преимущественно растут на литографических квадратиках размерами 80х80 нм ${ }^{2}$ нормально к поверхности, наследуя наноструктуру поверхности. Выращенные нанопроволоки состоят из одинаково ориентированных нанокристаллов высотой около 500 нм. Кристаллы $\mathrm{VO}_{2}$ растут в направлении [100]. Это же подтверждает огранка кристаллов типичная для этого направления (Рис. 1). 
Такие структуры перспективны в качестве новых устройств в основе которых лежит фазовый переход $\mathrm{VO}_{2}$ поскольку массивы представляют собой монокристаллы без межзеренных границ, они имеют малую площадь контакта с подложкой (что увеличивает долговечность устройств от разрушения вплоть до бесконечности) и дают полную интеграцию в современные 2D и 3D интегральные схемы (совместимы с кремниевой технологией).
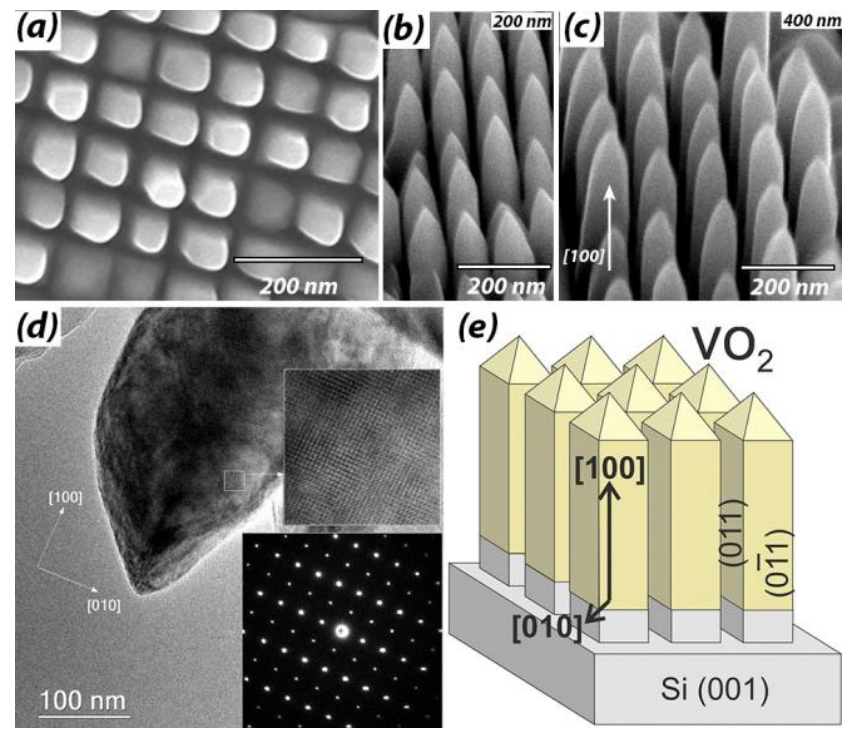

Рис. 1. СЭМ изображения упорядоченного массива нанопроволок VO2. (а) Вид сверху, (b), (c) Вид сбоку массива нанопроволок полученных после 2-х и 4-х часов синтеза соответственно (d) ПЭМ изображение отдельной нанопроволоки VO2 показывающее монокристалличность и направление роста [100] (е) Схематичное представление массива нанопроволок VO2 на нанострукутрированной поверхности кремния.

Таким образом, в данной работе мы представляем качественный переход от изучения одиночных, случайно выращенных кристаллов $\mathrm{VO}_{2}$ к формированию и изучению прецизионных массивов одинаковых нанокристаллов $\mathrm{VO}_{2} \mathrm{c}$ контролируемым местоположением, периодом, размером, ориентацией, составом и пр. Эта работа перспективна для практических применений. Например, можно интегрировать эти массивы в кремниевую схемотехнику и соединять заданные столбики с другими столбиками или формировать более сложные гетероструктуры. С массивами можно работать и дальше используя стандартную полупроводниковую технологию. Например, можно делать их тоньше селективным травлением. Закручивать пленку массива во внутрь или наружу. Перспективы работы не с одним кристаллом, а с целым массивом, периодическим, непериодическим, градиентным, с разной толщиной и высотой. Открывается целый спектр практических применений. Полученные массивы вертикальных столбиков перспективны для формирования умных метаматериалов, фотонных кристаллов чувствительных к температуре, свету, механическим напряжениям и пр.

\section{Литература}

[1] N. Davila, R. Cabrera and N. Sepulveda, IEEE Photonic Tech L 24 (20), 1830-1833 (2012).

[2] H. W. Liu, J. P. Lu and X. R. Wang, Nanotechnology 29 (2) (2018).

[3] I.P. Radu , et.al., Nanotechnology 26, 165202 (2015)

[4] B. S. Mun, et.al., Physical Review B 84 (11) (2011).

[5] Y. J. Chang, et.al., Physical Review B 76 (7) (2007)

[6] L. V. Yakovkina, et.al., J Mater Sci 52 (7), 4061-4069 (2017) 